\title{
Gender Differences in the Use of Linguistic Forms in the Speech of Men and Women in the Malaysian Context
}

\author{
Frankie Subon \\ Universiti Teknologi Mara, Shah Alam, Malaysia.
}

\begin{abstract}
Past researchers claimed that women and men are different in their speech from one another. The aim of this case study is to uncover the differences in linguistic features in the speech of men and women. The differences in the speech used by men and women are mainly marked by their choice in language forms, topics of conversation, etc. Some of the distinct features in the speech of men are they talk more than women, ask less questions and converse mainly on competitive matters, teasing, sports, aggression and doing things. Women focus on family, home, self, feelings and affiliation with others. However, findings by past researchers about which gender is more polite are rather contradicting. The present study replicates some of the major findings by yesteryear researchers. It is found that women use more polite forms of address than men, ask more questions and use more humours than men. Notably, men used slightly more of fillers, hedges and affirmatives than women. However, both genders are direct in their speech. It is also found that men's conversations focus on the topic of doing things i.e. works of entrepreneurs whereas women centre on the topics of home, self, feelings and affiliation with others. Analyzing the linguistic forms used, women appear more polite than men as they prefer using their ethnic group terms of address when addressing and referring to one another. Indeed, this study provides some insight and understanding about the differences in men and women's linguistics features in the Malaysian context which is made up of multi-racial society and rich in its varied cultures, customs, traditions, beliefs and religions.
\end{abstract}

Key words: linguistic features, gender, speech, cross-cultural communication, affiliation

\section{Introduction}

Women and men are different not only in terms of their physical attributes but also in terms of their speech in communication. Haas (1979) iterates that male speech and female speech have been observed to differ in their form, topic, content, and use. Previous studies on this issue believe that men may be more loquacious and directive as they use more nonstandard forms, talk more about sports, money, and business, and more frequently refer to time, space, quantity, destructive action, perceptual attributes, physical movements, and objects. On the other hand, women are often more supportive, polite, and expressive, talk more about home and family, and use more words implying feeling, evaluation, interpretation, and psychological state. However, it cannot be concluded that the differences in the speech of men and women are universal as these findings cannot be generalised to all contexts. Realizing this disparity between women's and men's speech and the variations of their speech across cultures and contexts, there is a need to pursue a research in this field to learn more about it in depth based on the Malaysian setting. With the varied differences in cultures, customs, traditions, beliefs and religions of Malaysians, there are bound to be differences in the results of this study from the western setting.

\subsection{Background of the study}

Notably, linguistic research on the differences between men's and women's language and speech have been pursued with some intensity during the last decade, and many features of language form or patterns of language use exhibiting sex-related variation have been identified, particularly for English (Shibamoto, 2001). In Malaysia, surprisingly, not many studies have been conducted in this field of research studies. Thus, there is a need to pursue this research in the Malaysian context as Malaysia is made up of a multiracial society that is rich in its cultures, customs, religions and tradition. The findings on gender differences by other researches from other countries which have different societal background may not portray the gender differences in Malaysia or other Asian regions. Furthermore, Shibamoto (2001) contends that although it has been suggested that differences in men and women's speech are probably universal, the nature of that claim to universality is unclear and hence fails to be an interesting source of explanation for linguistic fact. In view of this, the purpose of this case study is to identify the differences in linguistic features in the speech of men and women in the Malaysian context. 


\subsection{Purpose of the Study}

This study aims to look at the differences in speech of Malaysian men and women. The focus of the study will be based on the linguistic features listed by Lakoff $(1973,1975)$ such as questions, hedges, adjectives, intensifiers, verbosity and politeness and other features such as the usage of the form of address, humour and topics of conversation. This case study investigates the differences in the speech of five men and five women of some of the ethnic groups in Sarawak, Malaysia. These features are chosen precisely in this study because of their suitability with local setting and the amount of attention they have received in language and gender (Michael, Liaw, Muthusamy \& Veeravagu, 2010).

\subsection{Research Objectives}

a. To identify the differences in linguistic features in the speech of men and women.

b. To find out the most preferred topics of conversation by men and women.

c. To find out which gender used more polite linguistic forms.

\subsection{Research Questions}

a. What are the differences in linguistic features in the speech of men and women?

b. What are the most preferred topics of conversation by men and women?

c. Which gender used more polite linguistic forms?

\subsection{Significance of the study}

Notably, gender and cross-cultural communication is indeed an important area for research as its findings will be useful for various parties, namely to both genders, organizations: government and private, and the community at large as they will be able to obtain crucial knowledge about the differences between men's and women's linguistic features in speech. Besides, in the area of cross-cultural communication, it is pertinent to have some knowledge about these differences to help contribute towards the development of effective communication between and across genders in different contexts.

The findings from this present study will provide some crucial information about the differences in the linguistic features in the speech of men and women in local setting. This is beneficial and useful especially for local researchers in Malaysia as they will have a footing for doing further research relating to sociolinguistic and cross-cultural communication in local setting. Besides, the findings of this case study will add to the body of knowledge on the differences between male and female's speech and communication in a context which is made of varied and complex societal background.

\subsection{Limitations of the study}

This case study is only confined to a limited setting as all the participants chosen are the residents of one particular housing estate in Siburan District, Kuching. Besides, this study is limited to only ten Malaysians ( 5 males and 5 females). Thus, its findings cannot be generalized to a bigger population where more varied gender differences and cultural background have to be taken into consideration if inter-relationship of ideas were to be established.

\section{Literature Review}

According to Nemati \& Bayer (2007) there are some social differences between men and women. In connection to this, there are two most important theories on social differences between genders which need to be looked into for the framework of this study. These two theories are "difference theory" and "dominance theory".

They cited in Uchida (1992) that the "difference theory" contends that men and women who are of the same group will promote different ways of speaking if they live in different environment and culture. It is also called "two-culture theory". According this theory, cross-gender communication is considered as cross-cultural or bi-cultural communication. On the other hand, the "dominance theory" is about a condition whereby men and women are shaped by the culture and linguistic environment where there is inequality in power and status distribution in society. This theory, which is also called "power-based theory", focuses on male dominance and gender division. It is noted here that these theories show to us the influence of environment and culture on the speech of men and women across regions or contexts. Studies by previous researchers highlight some crucial results about the differences in linguistic features of men's and women's speech in terms of voice velocity, contents, functions, questions, politeness, etc.

In term of voice intensity, there are undisputedly some differences between males and females. Females' voices usually have different characteristics from the males and they exhibit different range of verbal skills from their male counterparts. According to Philip, Steele \& Tanz (1987) the different in voice quality may be accentuated by the beliefs about what men and women should sound like when they talk and any differences in verbal skills may be explained through differences upbringing. Notably, most observers like Baron (1986) 
describes women's speech as being different from that of men and these differences involving phonological aspects of language which are clearly distinguished in varieties of language. Consequently, these differences possibly can be explained and observed through matters having to do with how men and women use language in social interaction. Kremer (1974) stipulated in his study that women spoke less forceful than men and men sworn much more than women. This voice intensity in the speech of men and women coupled with other features will have its effects on politeness. Lakoff (1975) cited in Nemati \& Bayer (2007) stipulated that men use language which sounds assertive, adult, and direct, while women's language is immature, hyper-formal or hyper-polite and non-assertive. According to Michaelson and Poll (2001) when there is an absence of physical presence, there will be less awareness relating to rules of politeness related to face to face conversations.

However, Canary and Hause (1993) cited in Mulac (1998) have argued that meaningful differences in the communication strategies of men and women have not been found with any degree of consistency. Hence, more studies need to be pursued on this issue to come out with more conclusive findings.

In conversation involving both sexes, many researchers like James \& Drakish (1993) agree that men speak more than women and when men talk to men, they mainly focused on competitive matters and teasing, sports, aggression and doing things. Women, on the other hand, when talking to the same sex, the contents of discussion involve the self, feelings, affiliation with others, home and family. Distinctively when the two sexes interact, men tend to take the initiative in conversation but there seem to be the tendency to achieve (divergence) some kind of cooperation on the part of men to accommodate so far as topics are concerned. Here men speak less aggressively and competitively and women reduce their amount of talk about home and family. Nevertheless, there is a need to consider other factors that influence people's speech or conversation such as environment and culture as mentioned in the "difference theory" and "dominance theory." The results may be different if it is done among participants of different culture who live in a different environment.

Culturally in most community, James and Drakish (1993) in their study, observed that women are expected to gain greater ground than men to serve the function of establishing and maintaining personal relationship whereby they are to keep the interaction following smoothly and to show goodwill toward others. This weaker gender is further expected to share personal feelings and other socio-emotional matters relevant to interpersonal relationship more than men. Based on Zimmerman \& West (1975), on the study of cross-sex interaction, indicates that men usually interrupt women to exhibit domination and control over the conversation.

In contrast, as James \& Clerke (1993) observed in their study, stated that any interruption made by women were to seek cooperation and for rapport-building. They also observed that women asked more questions than men, encourage others to speak, using fillers $(\mathrm{mhmm})$ indicating that they are listening and they do not protest as much as men whenever being interrupted. On the other hand, men often interrupt, challenge, dispute and ignore more, dominate the conversation, may use fillers ( $\mathrm{mhmm}$ ) to indicate 'agreeing', decide the topic and are inclined to make categorical statement.

Similarly, to substantiate linguistic differences between men and women, Maltz \& Borker (1982) maintain that women and men observe different rules in conversing in which they have different views on various norms. For example, men view "questions" as request for information while women view questions as a part of conversational maintenance. Furthermore, women view a kind of aggressive linguistic behaviour as personally directed, negative and disruptive while men consider such behaviour as a way of organizing a conversation. For any problem-sharing and advice-giving, women tend to discuss, share and seek reassurance while men tend to look for solution, give advice and even lecture to their audiences. All this characteristics in men and women's speech may have in one way or another affect their politeness to a certain extent in their conversation.

Surprisingly, there is an inconsistency in research findings relating to men's and women's politeness in conversations. Gender differences in politeness, rules and tradition suggest that women are supposed to behave more politely than men (e.g. Becker \& Smenner, 1986; Brown, 1980; Cashion, Cody, \& Erickson, 1986; Gleason, Perlmann \& Greif, 1984; Smith, 1990). This is also supported by Brown (1980) who suggests that women generally demonstrate more politeness strategies than men do. However, some writers report that men are more polite than women. For instance, men use polite markers more appropriately than women in public.

There are even some studies indicating that there is no gender difference in politeness. Here men and women employ an equal number of polite forms such as "please", "Thank you", and "greetings". Drawing on Brown and Levinson's work, Janet Holmes argues that women generally are more polite than men. She describes that most women like to talk more and they consider talking as an important means of keeping in touch, particularly with tier friends and inmates. The functions of language to them are to establish, nurture and develop personal relationship. Men, however, tend to see language more as a tool for obtaining and conveying information. Holmes further suggests that women are more likely to use positive politeness than men as she asserts that "women's utterances show evidence of concern for feelings of the people they are talking to more often and more explicitly than men's do..." (Holmes, 1995) 
According to Wardhaugh (1988), to explain gender differences in language behavior there are several claims that may be made. (a) Since men and women are biologically different and this contributes to women predisposed psychologically to be involved with one another and to be mutually supportive and noncompetitive. Men, on the other hand, are innately predisposed to independence and to attain power rather than solidarity. (b) Language behaviour reflects the social dominance of men as they try to dominate, decide a topic, interrupt, and so on regardless of sex i.e. among men and particularly toward women. (c) Linguistically, men and women are social being who have learned to act in certain ways, As language behavior is largely learned behaviour, men and women learn accordingly to what they are expected to be of importance in a particular society or community. In Malaysia, for instance where the society is made up of different races with varied and complex cultures, customs and traditions, and with the practice of inter-marriage among races, there are bound to an assimilation of some nuances including their languages and speech behaviour.

Surprisingly, limited studies have been pursued on the linguistic features of the speech of men and women. Quite recently, Michael, Liaw, Muthusamy \& Veeravagu (2010) carried out a study that aims to look at the differences in speech styles of Malaysian men and women. The study limits itself to describe language use, in particular the different usage of women and men as speakers in the use of five linguistic features; questions, hedges, adjectives, verbosity and politeness. Analysis from their study shows that in the fifteen minutes talk the striking overall female difference was in the use of questions, where females outnumbered males. There was also a difference in the use of fillers, in the proportion of qualifiers used and individual differences in types of qualifiers used. Female presenters showed that they were more assertive and confidence in their conversation.

Besides, there seemed to be a tendency among female presenters to use a higher frequency of affirmative words. The findings also provide evidence that one male speaker made many false starts and repeated words as a hesitation device. However, the differences in term of politeness could not be determined as the assumption cannot be made that male speakers used intensifiers at a higher rate than the females. Although this study has provided some information about the differences in the speech of men and women, there are limitations in this study. The study is limited to only four Malaysian (two males and two females) television and radio presenters. Thus, there is a need to explore further into this area of research in the Malaysian context with samples of different cultural or societal backgrounds.

\subsection{Population}

\section{Methodology}

Malaysia as a multi-racial society is made up of different races with diverse cultures, customs, religions and beliefs. Its varied cultural background and ethnic languages makes it a suitable setting for doing research in this area of sociolinguistic and cross-cultural variations. Specifically, the setting of this present study i.e. Siburan which is a small district in Kuching is also a suitable setting for this study as it is a place where people of different backgrounds live. The community is made up of different races such as Bidayuhs, Chinese, Ibans, Malays, Melanaus, Bugis, and others. This district has a total population of 29,179,952 people in the year 2012, residing mainly in Siburan town and its surrounding areas. Siburan town is usually busy with people early in the morning and late in the afternoon where people from all walks of life meet to do their daily chores. Communication between people of different races can be heard at the heart of the town which is the centre of attraction as people from surrounding villagers come to Siburan to buy their needs. It is here that we can catch the glimpse of people of differences races are engaged in conversations.

The main language use in communication is 'Bahasa Pasar' or 'Bahasa Melayu Sarawak' especially between people of different races. It is also a common sight to see people having conversation at coffee shops and food stalls. Thus, this provides a strategic setting for the researcher to do this research. It is an exciting experience to listen to people from different races converse with one another. Besides, gathering and community work sometimes takes place once a month for example women fellowship, church activities, community activities and etc. It is during these activities that women and men gather with their company of the same gender. Sometimes, this fellowship or gathering takes place at their home during their free time. Thus, this provides opportunity for the researcher to collect data for this study.

\subsection{Participants}

The participants for this case study are selected randomly. There are five women and five men selected and they are made up of different races and have different careers. They all live in Siburan District, Kuching, where the researcher lives. The men are made up of two races - four Ibans and one Bidayuh. Three of the participants work at the Western Digital factory in Pending, Kuching. The other two participants work as labourers. They all have known each other for almost ten years and attended the same Anglican Church at the same vicinity. The researcher approached them while they were engaged in a conversation. They conversed in Iban language as a majority of them are Ibans and the Bidayuh participant could also communicate in Iban language. Permission was obtained from them, informed that their identities would be kept confidential and the 
purpose of this research was also explained to them. After the recording, a semi-structured interview was carried out.

The five women who are chosen randomly for this research also comprise of different races -two Ibans, one Bidayuh, one Kenyah and one Lun Bawang. They also have known each other for almost ten years and have different careers. Two are housewives, one teacher and two doing small business like selling cakes and traditional handicrafts. They also attend the same church in Siburan. They used to meet every Sunday and also in women fellowship which is also held every Sunday evening. Apart from that, they sometimes organize other gathering such as home fellowship and a gathering while eating 'ulam' or local salad and 'linut', a traditional Bidayuh delicacy. Permission was also obtained from them to participate in this research and informed that their identities would be kept confidential and the purpose of this research was also explained to them.

\subsection{Data collection methods}

\subsubsection{Recording}

The data is recorded in non-numerical form where the conversation recording will be transcribed (Nunan, 1996). This is employed in order to gather data in natural language (Rugg \& Petre, 2007) Recordings of participants' conversations were done on April 5, 2011 using a tape recorder. The recording of the women conversation was done at the researcher's house when his wife was having a gathering with her four close friends eating traditional delicacy 'linut' and 'ulam' or salad. A 40 minutes recording was taken and at the same time observation was done. After the recording, the participants were interviewed. The recording of the men participants was done while they were chatting at a banana fritters stall. This recording was also done in 40 minutes. Then, both conversations were transcribed by doing translation to English as Iban and Malay languages were used in the women conversation and Iban language was used by the men participants. This transcription was then analysed by categorizing the data into themes or categories. Then comparison between women and men's linguistic features was made by referring to the themes or categories done earlier to elicit results to answer the research questions. Besides, semi-structured interviews were carried out to ascertain the results obtained from the transcribed data.

\subsubsection{Direct Observation}

Rugg \& Petre (2007) stated that direct observation requires researchers to observe something directly, such as watching how people behave in supermarkets. In this study, the researcher observe the participants who are engaged in conversations and notes are taken. The rationale of using this is it shows something vividly without the filtering effects of language.

\subsubsection{Semi-structured interview}

Some (7) predetermined questions were prepared before the interview and other spontaneous questions will be asked when necessary. This is in accordance with Rugg \& Petre (2007) description that semi-structured interview comes in between structured and unstructured interviews whereby some predetermined topics and questions are prepared, but space is left for following up interesting topics when there are opportunities.

\subsection{Data analysis}

The data obtained from the interviews and transcriptions were analysed by referring to the codes or themes and frequencies used in the analysis and significant features were noted to come up with the findings of the study. The results obtained from this data analysis helped to answer the research questions. The data was analysed through the procedure of protocol analysis (Newell \& Simon, 1972, Olshavsky, 1977, Mann, 1983) cited in Seliger \& Shohamy (2008). This data will determine the analysis rather than the analysis imposing predetermined categories on the data (Seliger \& Shohamy, 2008). Listed below are the stages involved in analyzing those data:

a. Written transcriptions are made of the verbal protocols for each subject.

b. The protocols are carefully reviewed and notes are made relating to the linguistic features used by both genders according to themes or categories.

C. A comprehensive list of all the linguistic features used by both gender will be compiled.

d. This list will be analysed in an attempt to collapse and combine certain themes or categories. A finite group of categories and sub-categories was formulated. These categories then became the criteria by which each of the protocols is analysed and the frequency of occurrence for each type of linguistic features is calculated.

e. Each answer to each question in the interview will also be analysed according to the categories formulated.

(Adapted from Seliger \& Shohamy (2008)) 


\section{Findings}

\subsection{The differences in linguistic features in the speech of men and women.}

After analysing the transcripts of conversations of both genders and the data analysis based on themes or categories, it is discovered that men and women exhibit some distinct linguistic features in their speech. These differences can be seen in the use of the terms of address, humour, directness and indirectness in speech, questions, politeness and intensifiers and topics of conversations.

\subsubsection{Terms of address.}

In linguistic, terms of address are used in addressing others to attract their attention or for referring to them in the course of a conversation. Murphy (1988) describes forms of address as socially driven phenomena. In other words, linguistic forms that are used to address others can mirror the complex social relations of individuals in a speech community (Paulston 1976; Trudgill 1983; Chaika 1982).

In this present study, it is discovered that the women respondents used the terms of address more frequently than the men. In the 40-minute conversations among the women, it is apparent that they used different terms of address. The forms of address used are connected to their family units as they prefer to use the forms of address such as 'Mak Ben' or Ben's mum, 'Mak Girl' or Girl's mum, 'ibu' or aunt and 'Cikgu Bity' or Teacher Bity. During the researcher's observation and throughout the conversations, there are five forms of address used. In the semi-structured interviews conducted after the conversations, they reasoned that these forms are used to show politeness. Uniquely, this form of address is used by all the four races - Bidayuh, Iban, Lun Bawang and Kenyah. Among the Ibans, for instance, they are familiar in addressing married women with children by associating them with the names of their eldest sons or daughters such as 'Indai dom' or Dom's mum. The Kenyahs also used the same form of address in their own language such as 'We'Esther' for Esther's mum. They all said that they are used to using this form of address among themselves and seldom called one another by name unless they are relating one another to somebody else.

In contrast, men do not use any terms of address in their conversation. This is probably because the topics of their conversation are mainly about jobs where there are less requests and questions. Besides, the fact that the conversation flows quite fast and a lot of sudden cuttings are used as part of the strategies in their communication discard them from addressing one another. Nevertheless, through interviews conducted they all claimed that they do use the forms of address as used by the women respondents such as 'Apai Dom' or Dom's dad, 'Apai Mang' or Mang's dad in their conversation with other speakers. This was ascertained when one of them recounted about a relative who grows jatropha in conversation 4: Biodiesel, he addressed him as 'Apai Ina' which refers to Ina's father.

\subsubsection{Humour}

Many linguists say that humour is a complex multi-faceted phenomenon. According to Graesser et al. (1989: 149), humor and laughter are relieving mechanisms that occur to release the tension that is associated with hostility, anxiety, conflict, or sexuality.

In this study, humour is found to be the prerequisite of women's conversation. It is frequently used to express excitement, promote a conducive atmosphere for conversations and establish a closer relationship. Some of the humours used contain implicatures although most do not. Some of the humours used are as follows;

\section{Conversation 1: Humour}

5 MB: Oh, agi bersolek lu Mak Ema tu.

(Oh, Ema's mum is still grooming herself.)

6 (All giggling)

7 ME: Bersoleklah dulu.

(Grooming first)

8 BB: Yalah mesti mau cantik-cantik.

(Of course need to be pretty)

9 ME \& BB: giggling

10 ME: Kalau tidak cantik tidak tidak menggoda itu.

(If not pretty, not attractive.)

11 BB: He! He! He!

12 MB: Cantik-cantik makan linut!

(Pretty eating 'linut!')

13 ME: Ha! Ha! Ha! 
In, the above conversation, they are making a humour as they talk about their friend who has not come to the gathering. They jokingly say that she is still grooming herself to look attractive and in turn $12, \mathrm{MB}$ is creating an implicature in her humour as it can carry several meanings. One, it could mean she is curious about $r$ why she needs to look pretty in attending such a gathering of eating 'linut' Second, it is meaningless as it is an incomplete sentence and uttered just to create humour. This is shown as ME bursts in laughter. Humour is used frequently to create a relaxed atmosphere as they prepared the ingredients or delicacy for their 'linut' and 'ulam' (salad). Thus, their conversations are filled with giggles and laughter and humours are present in all the six segments of their conversation. This is one feature of women's conversation in this study which makes it different from the men's.

Men, in this present study do not use humour in their conversations. This is partly because of the topic of their conversations which focuses mainly on occupations. In other words, they converse about something rather factual and informative in nature. This can be seen in the example below.

\section{Conversation 1: Rearing cat fish in canvas cage.}

B: (cutting) Iya dalam tiga bulannya, dalam 200, 200 1/2 gramlah, 200 1/2 ke 300 gram. Enti baka ba KL din kemari, aku meda sida bejual ba tamu deh, dalam 200 1/2 gram ya, mesai ulu duku eh. Ba KL din, udah dibuai urang pala, udah dibuai orang perut, baru 5 Ringgit setengah sekilo.

(Within three months, it's already about 200, 200 1/2 grammes, 200 to 300 grammes. When I was in KL before, I saw them selling it, about $2001 / 2$ grammes, as big as the handle of a parang. In KL, its head is already removed, digestive organ removed, only 5 ringgit half a kilogramme.)

In the above utterance, $\mathrm{B}$ is giving information that in three months, a cat fish weighs 200 to 300 grammes in size. He also recounted his past experience about seeing people selling cat fish (which was reared in canvas) sold at a reasonable price of RM5 only half a kilogramme. Obviously, it is factual and informative in nature which does not require him to use humour. There are a large number of utterances in this pattern throughout the men's conversation.

\subsubsection{Directness and indirectness in speech}

Levine (1985) explains directness as a result of a modern, complex society where being to the point, clear, simple (i.e. not to say more, nor less, than required), and objective has become necessary in order to avoid misunderstandings. Indirectness characterized by ambiguous language with embellishments harbouring multiple associations and rich shades of emotions on the other hand, is tied to traditional values of art, refinement and politeness and serves various functions. Asians are generally direct in their speech than Westerners. This is clearly demonstrated in the conversations among these multi-racial women speakers. All of them are direct in their speech. In the interview conducted, they all claimed that they are direct in their speech and according to LT, she is very direct in her speech and she realises that sometimes people get hurt when conversing with her. When asked whether her ethnic group is direct in speech, she commented that her directness cannot be associated with her ethnic group as it is due to her own character. Some examples of directness in speech can be found in the conversation below.

Conversation 3: Women Fellowship

12 ME: Isteri cikgu Bong ada?

(Is Mr Bong's wife present?)

13 BB: Tidak ada.

(No, no)

14 SS: Nadai ga bini Cikgu Bong pia...ukai enda iya ga te mai? (giggle)

(So, Mr Bong's wife was't present too...wasn't it she who invited?)

15 BB: Iya bedau abis tution. Kami empat sigi bisi bah!

(She hasn't finished giving tuition.) The four of us were around, anyway.)

In this conversation, SS directly questions Mr Bong's wife who has invited them to attend the Women fellowship which was held on Sunday evening but she herself did not turn up. She sounds sarcastic in her comments. However, BB understands and tries to cover up by saying that it is alright since there were four of them coming. Despite their direct pattern of speech, there is also an occasion whereby indirectness is used although it is a rare feature as in the example below.

Conversation 3: Women Fellowship.

16 SS: Aku kemari ka enggau, kawan ku talipon madah ka pensyarah ari Unimas nya ka betemu enggau aku malam tadi, nya aku nadai nyadi nurun.

(Actually, I wanted to join but my friend called telling me that a lecturer from 
Unimas wanted to see me last night. So, I decided not to go.)

Here, SS is telling the other interlocutor, BB that a friend called her telling that a lecturer from Unimas wanted to see her that evening. So, she could not make it to the women's fellowship activity known as 'pocopoco'. To avoid saying it directly, she gives reason for why she could not make it to the weekly activity of the women's fellowship. According to one of the participants, MB, she claimed that she tends to be direct in verbal communication. However, there are situations whereby she will be indirect in her speech especially when relating something very personal to close friends.

Men also claimed that they are direct in their conversation. This is prevalent in their conversations in this present study. This is clearly shown in the following example.

Conversation 4: Biodiesel

E: Uji dik nanam jetropa.

(Try to plant jatropha.)

B: Enggai!

(I don't want.)

E: Bisi bala.

(There's a relative.)

B: (Suddenly cuts in) Udah ujiku, bisi ku dia kemari bai ku minta ba Apai Alex.

(I've tried it, I asked some from Alex's father yesterday)

A: Enggai tumbuh?

(It doesn't grow.)

B: Enggai tumbuh.

(Doesn't grow.)

C: Enda entu deka idup.

(It doesn't grow well.)

B: Neningginya, udahnya sekali meda udah kena ai tu tadi ni ye.

(This height, suddenly it died because of the rain.)

The conversation above shows that B is very direct in his response when E suggests that he can try to plant jatropha, a type of plant that produces fruits which can be processed into diesel. However, in the next turn, he reasons that he has tried it but failed.

\subsubsection{Intensifiers}

Intensifiers express both referential meaning (degrees of certainty) and affective meaning (politeness). Intensifiers have been classified as 'boosters' (Quirk et al., 1985) 'strengtheners' (Brown \& Levinson, 1987) and 'up-graders' (House \& Kasper, 1981). Researchers have also considered this form as politeness device (Shinanoff, 1977; Brown and Levinson, 1987).

As opposed to the finding by Nemati \& Bayer (2007), the women in this present study do not use intensifiers (refer to Appendix 1). The linguistic forms used are less intense as the topics of their conversations are on petty issues relating to personal and social life. Among others, they talk about their women's fellowship, household chores such as drying pillows, personal experiences such as the experience of Mdm BB and etc. In short, they converse in a relaxed atmosphere and use registers which emphasize very minimal impositions in their speech. This is portrayed in the following utterances. The same applies to the men, they do not use any imposition to express their ideas as they converse mainly on doing things and no intensifiers and imposition are required.

\subsubsection{Questions}

Another obvious difference between women and men linguistic feature is the use of questions. Confirming the research of past researcher by James \& Clerke (1993) who observed that women asked more questions than men, encourage others to speak, using fillers indicating that they are listening and they do not protest as much as men whenever being interrupted. In the present study, it is found that women asked more questions i.e. 13 questions than men with only 5 questions (refer to Appendix 1). They asked to request for information about something as seen in the example below.

Conversation 1: Humor

$1 \mathrm{MB}$ : Ooi!, ooi! Manah amat baju dik, dini dik meli?

(Wow! wow! Your dress is beautiful, where did you buy it?)

2 Bb: Baju anak buah aku, enda cukup, passing. Eh, Mak Ema udah tekkah? 
(My niece's dress, it doesn't fit her. So, she gives it to me. Eh! Has Ema's mum come?)

3 MB: Bedau. Ni dik nadai mai ya tadikah?

(Not yet. Why didn't you invite her?)

4 BB: Aku piker dah jalai dulu.

(I thought she has left earlier.)

In the above utterances, it is clearly shown that $\mathrm{MB}$ and $\mathrm{BB}$ used questions frequently to converse and this helps to keep the communication going and allow space for one another to engage in the topic of conversation. Questions are found in all the six topics of conversation and there are varieties of questions asked such as asking why?, who?, what?, Has?, Where?, etc.

Men, on the other hands asked minimal questions that is only five times in the four conversations. They converse continuously without asking questions but just present their opinions about the topic of discussion spontaneously, continue a conversation when the other speaker pauses or stops and sometimes simply cut in even though the other speaker is still talking. This appears rude but being friends who have known one another for almost 10 years, they are not bothered by it.

\subsubsection{Verbosity}

Verbosity is a feature used to characterize how much a speaker talked. In this study, the number of turns and the number of words each person produced in a conversation is counted to identify verbosity in speech.

Table 1 The number of turns taken and the number of words spoken by the male speakers.

\begin{tabular}{ccccccccc}
\hline & \multicolumn{2}{c}{ C 1 } & \multicolumn{2}{c}{ C 2 } & \multicolumn{2}{c}{ C 3 } & \multicolumn{2}{c}{ C 4 } \\
Speakers & Turns & Words & Turns & Words & Turns & Words & Turns & Words \\
\hline A & 3 & 76 & 7 & 46 & 6 & 58 & 5 & 17 \\
B & 2 & 59 & - & - & 4 & 25 & 6 & 34 \\
C & 2 & 9 & 4 & 13 & 4 & 27 & 2 & 6 \\
D & 2 & 18 & 1 & 20 & - & - & & \\
E & - & - & 4 & 26 & 4 & 11 & 7 & 108 \\
\hline
\end{tabular}

Table 1 shows that in almost all the four conversations i.e. in Conversation 1, 2 and 3, it is found that speaker A is monopolizing the conversation. This is clearly demonstrated in Conversation 2: Growing lemon grass where speaker A dominated the conversation by taking 7 turns and produced 46 words as compared to $\mathrm{C}$ with 4 turns and 13 words, E with 4 turns and 26 words and B with 1 turn and 20 words. Speaker A also monopolises the conversation in Conversation 1 with 3 turns and 76 words and in Conversation 3 with 6 turns and 58 words. On the other hand, speaker E monopolises the conversation in Conversation 4 with 7 turns and 108 words. Thus, in this present study it is found that men tend to have higher verbosity than women.

Table 2 The number of turns taken and the number of words spoken by the female speakers.

\begin{tabular}{cccccccccccccc}
\hline & \multicolumn{2}{c}{ C 1 } & \multicolumn{3}{c}{ C 2 } & \multicolumn{2}{c}{ C 3 } & \multicolumn{2}{c}{ C 4 } & \multicolumn{2}{c}{ C 5 } & \multicolumn{2}{c}{ C 6 } \\
Speakers & Turns & Words & Turns & Words & Turns & Words & Turns & Words & Turns & Words & Turns & Words \\
\hline MB & 4 & 24 & 3 & 24 & 2 & 6 & - & - & - & 4 & 19 \\
BB & 4 & 25 & 3 & 12 & 6 & 40 & 4 & 45 & 5 & 91 & 3 \\
ME & 3 & 13 & 2 & 13 & 3 & 19 & 2 & 2 & 1 & 2 & 4 \\
SS & - & - & 2 & 10 & 5 & 52 & - & - & - & - & - & - & 23 \\
LT & - & - & - & - & - & - & 2 & 16 & 4 & 26 & 2 \\
\hline
\end{tabular}

Table 2 shows that each female speaker has more or less a fair contribution in the conversation. They take almost the same number of turn taking in almost all the conversation except for Conversation 3 and 5 whereby MB only takes 2 turns and uttered 6 words and ME only takes 1 turn and uttered 2 words. Although in a number of conversations a speaker speaks longer than other interlocutors, this fair distribution in turn taking has avoided speakers from monopolising in a conversation. For example in Conversation 1, MB takes 4 turns and 24 words, BB takes 4 turns and 25 words and ME with 3 turns and 13 words.

\subsubsection{Adjectives}

In the use of adjectives (refer to Appendix 1) for approvals, women used it more frequently than men i.e. 6 times as compared to the men who do not use any of these adjectives. This finding is consistent with the finding of Lakoff (1975) whereby women used more adjectives than men. In the present study, women use adjectives such as attractive, pretty, beautiful and big as approvals for their friends. 


\subsubsection{Fillers, hedges and affirmatives}

Surprisingly, both genders used very few fillers, hedges and affirmatives in their speech (refer to Appendix 1). There are only slight differences in the use of these features whereby men are using these features slightly more than women opposed to findings by past researchers. Men only used fillers 2 times such as "aah..." and "emm..." while women only used it once i.e. "eh..." For hedges such as "I think...", men used it 3 times while women only used it 2 times. On the other hand, men used affirmatives such as "yes" three times but women only used it once.

\subsection{What are the most preferred topics of conversation by men and women?}

In the 40-minute conversation, it is discovered that the men speakers prefer to talk about jobs or doing things. With reference to the transcription, they conversed on the topic of entrepreneurship. The breakdown of the topics for the four conversations is shown below.

Conversation 1: Rearing cat fish in a canvas tank.

Conversation 2: Growing lemon grass

Conversation 3: Growing Bamboo

Conversation 4: Biodiesel

All the above topics are related to doing things which are the focused of conversation when men speak to men as pointed out by James \& Drakish (1993) In interviews with all the five participants, four of them say that their conversations usually focus on jobs. This according to participant $\mathrm{E}$ is because men are the bread winner of the family. Only one participant says that men usually talk on something general such as sports, something humorous, jobs, etc.

On the other hand, women focus on different topics than men. They talk on issues related to self, home, feelings and affiliation with others. This is listed in the breakdown of topics in their communications below.

Conversation 1: Humour

Conversation 2: Skinning of mangoes

Conversation 3: Women Fellowship

Conversation 4: Drying pillows.

Conversation 5: BB's experience

Conversation 6: Taking things

This also reaffirmed a finding by James \& Drakish (1993) that women when talking to the same sex, the contents of discussion involve the self, feelings, affiliation with others, home and family. This is also ascertained by the responses obtained in interviews with the five women participants who say that they usually talk about family, personal feelings, religious activities and home. Another difference obtained is men speak more than women in this present study. This is proven when men tend to speak with longer and more utterances than women as in Conversation 1: Rearing cat fish in canvas tank. Besides, men also tend to talk about a topic more than women as they talk about only four main topics within 40 minutes whereas women converse on six main topics. This present finding also confirmed the finding by James \& Drakish (1993) that men speak more than women.

\subsection{Which gender used more polite linguistic forms?}

Analysing the transcription of the 40-minute recording for each gender, it is discovered that women used more polite linguistic forms than men. This is ascertained as women use polite forms of address when addressing one another as discussed early in this chapter even though both genders do not use any intensifiers in conversation. This finding confirmed the finding by Brown (1980) that women generally demonstrate more politeness strategies than men do The forms of address used are such as 'Mak Ben' or Ben's mum, 'Mak Girl' or Girl's mum, 'ibu' or aunt and 'Cikgu Bity' or Teacher Bity. During the researcher's observation and throughout the 40-minute conversation, there are about 5 forms of address used. Some examples of this can be seen in the following utterances.

Conversation 1: Humour

5 MB: Oh, agi bersolek lu Mak Emu tu.

(Oh, Em's mum is still grooming herself.)

$6 \quad$ All giggling 
Conversation 2: Skinning mangoes

1 MB: Eh.. nama dipunsi kami duai Mak Girl, nya Cikgu Bity udah datai.

(Eh.. Girl's mum, what should the two of us be skinning off? There Mdm Bity (a teacher) has come.)

On the contrary, men do not use any forms of address with one another in their conversation in this study. In the interviews conducted after the conversations, the women respondents reasoned that these forms are used to show politeness. The Men participants claimed that they do use polite forms such as 'Apai dom' or Dom's dad, 'Apai Mang' or Mang's dad and etc when conversing with other speakers who are not close to them.

\section{Discussion}

This study has ascertained some of the major findings about the differences in the linguistic features in the speech of men and women and provided answers for the research questions outlined for this study. Women's speech is very much influenced by their choice of linguistic forms. They prefer to use a lot of questions to enquire about information which indirectly helps to develop quite a fair participation especially in terms of turn taking by all the interlocutors. Thus, the women's speech is shorter in forms than the men's and they switch from one topic to another in a shorter time than men.

Besides, polite forms of address are used in addressing each other and interestingly all the different ethnic groups used the same form of address which is associated with the speaker's son's or daughter's name. Throughout their conversations, there are five forms of address used by the women respondents. In the semistructured interviews conducted after the conversations, they reasoned that these forms are used to show politeness. It is unique that all the four races - Bidayuh, Iban, Lun Bawang and Kenyah are familiar in addressing married women with children by associating them with the names of their eldest sons or daughters such as 'Indai Dom' or Dom's mum. They all said that they are used to using this form of address among themselves and seldom called one another by name unless they are relating one another to someone else.

Humour is frequently used by women speakers to create a relaxed and gaiety atmosphere that is filled with excitement and joy with the sudden surged of giggles and laughter in their speech. Men, in contrast used minimal questions in their conversations and the absent of humour discards giggles and laughter. As a result, one speaker tends to monopolize the conversations and produces long utterances and talks about a particular topic for a long time. Comparing their transcribed utterances, it is found that women are more polite than men as they are using polite forms of address. Unlike women, men do not use polite forms of address in their conversations or speech. This feature of the men's speech ascertains Kremer's (1974b) finding that assertiveness was observed as part of the male stereotype and by Lakoff (1975) who suggested that women's speech is nonassertive. This concept is also supported by other writers such as Haas (1979) who claims that women's speech is said to contain more euphemism, politeness forms, apology, laughter, crying, and unfinished sentences. Although the men claimed that they do use the polite forms of address, it is found that they do not use it in their conversation during this study. The degree of politeness may have been affected as they tend to ignore addressing one another probably because they are very close to one another. This bond in relationship and rapport with each other might have caused them to overlook the accepted norms or ethics in spoken discourse.

Despite some of these distinctive features in men's and women's speech, it is also discovered that men and women share the same features in their speech in terms of directness and indirectness in speech. Both genders are direct although there are some instances whereby they are indirect in their speech. This is clearly demonstrated as there are no terms in the ethnic groups which can be used in place of 'please', may, could etc. Hence, their speech may sound direct and rude to other interlocutors. Notably, men used slightly more of fillers, hedges and affirmatives than women. This finding is in contrast with findings by Lakoff (1975) who found that women used more fillers, hedges and affirmative words than men. Both genders use very little of these linguistic features probably because they are communicating using their ethnic or first language which they are fluent and competent in. Furthermore, the topics of their conversation do not require them to give factual information. They are just talking about petty issues relating to their daily lives, hence, they do need to think hard about what to say.

In this study, it is discovered that men focus on jobs as the topic of conversation in contrast of the women who talk more on family, home, affiliation with others, self and feelings. This is consistent with the findings by other researchers such as Haas (1979) who contends that they are reputed to talk more about home and family and tend to be more emotional and positively evaluative. Further, he added that women's speech is stereotyped as nonassertive, tentative, and supportive while men are reputed to talk more about sports, money, and business.

This research has indeed revealed a unique gender differences among some of the ethnic groups in Sarawak, Malaysia in spoken discourse. The differences in speech are marked in terms of the use of the terms of 
address, questions, adjectives, verbosity, politeness and topics of conversation. However, only slight differences are revealed in other linguistic forms such as the use of fillers, hedges and affirmative and no differences are discovered in the use of intensifiers.

\section{Conclusion}

The present study has revealed that there are differences in linguistic features in the speech of men and women and this ascertained the claims made by past researchers. Although there is a similarity in term of directness in speech, the differences are prevalent in the use of the terms of address, humour, questions, verbosity, adjectives, politeness and the topics of conversations. Nevertheless, only slight differences are found in the use of other features such as fillers, hedges and affirmatives but no difference is identified in the use of intensifiers. It must be noted that the results of this study may not be applicable to other men and women in other places and of other races as the respondents are made up of only the randomly selected men and women among some of the ethnic groups in Siburan District, Kuching who have their own characteristics that may be different from men and women in other districts, towns, regions and countries. Furthermore, only a small sample of five men and five women are used in this study, hence, the results cannot be generalized to a bigger population. It is important to note here that there is no definite answers relating to gender differences in speech and communication. Canary and Hause (1993) cited in Mulac (1998) have argued that meaningful differences in the communication strategies of men and women have not been found with any degree of consistency. Despite these limitations, the findings in this study enable us to understand more about the variations in the linguistic features of men and women in the Malaysian context.

Besides, the understanding about these differences in speech will help men and women to understand one another better and develop an effective communication across genders. According to the Conflict Research Consortium University of Colorado, USA, in its article 'Cross-cultural communication strategies,' it is emphasised that the key to effective cross-cultural communication is knowledge. It is necessary for people to know about the potential problems of cross-cultural communication and make a conscious attempt to overcome these problems. Effective communication is enhanced when there is awareness about gender differences in linguistic features in the speech of men and women and the importance of respect for one another. For future research, it is crucial to see the differences between men and women's linguistic features when they engaged in cross-gender and cross-ethnic communication.

\section{References}

[1] Haas, A. (1979) Male and female spoken language differences: Stereotypes and evidence. Psychological Bulletin, Vol. 86, No. 3, 615-626.

[2] Shibamoto, J. S. (2001) Language, gender and sex in comparative perspective. Cambridge University Press, New York.

[3] Lakoff, R. (1975). Language and women's place. New York, NY: Harper and Row.

[4] Michael, A. S., S. C. Liaw, Muthusamy, C. \& Veeravagu, J. (2010). Gendered-linked differences in speech styles: Analysing linguistic and gender in the Malaysian context. Cross-cultural Communication Vol.6 No.1 2010

[5] Nemati, A \& Bayer, J. M. (2007) Gender differences in the use of linguistic forms in the speech of men and women: A Comparative study of Persian and English. Retrieved April 16, 2010 from http://salr.net/Documents/AzadehBayer2007.pdf

[6] Uchida, A. (1992). When difference is dominance: A critique of the anti-power-based cultural approach to gender differences. Language in Society, 21, 547-568.

[7] Philip, S. U., S. Steele, C. Tanz (1987). Language, gender and sex in comparative perspective. Cambridge University Press, New York.

[8] Baron, D. (1986). Grammar and gender. Yale University Press, New Haven.

[9] Kremer, C (1974). Wishy-washy mommy talk. Psychology today.

[10] Mulac, A. (1998). The gender-linked language effect: Do language differences really make a difference? In D. Canary \& K. Dindia (Eds.), Gender differences and similarities in communication: Critical essays and empirical investigations of gender and gende in interaction, (pp. 127-153). Mahwah, NJ: Laurence Erlbaum.

[11] James, D. \& J. Drakish (1993). Understanding gender differences in amount of talk. A critical review of research.

[12] Zimmerman, D. H., \& West, C. Sex roles, interruptions and silences in conversation. In B. Thome \& N. Henley (Eds.), Language and sex: Difference and dominance. Rowley, Mass.: Newbury House, 1975.

[13] James, D an S. Clerke (1993). Women, men, and interruptions: A critical review.

[14] Maltz, D.N. \& R.A. Borker (1982). "A cultural approach to male-female miscommunication." In J. Gumperz (Ed.), Language and social identity. Cambridge: Cambridge U.P.

[15] Brown, Penelope. (1980). How and why women are more polite: Some evidence from a Mayan community. In Sally McConnellGinet, Ruth A. Borker, \& Nelly Furman (eds.), Women and language in literature and society. New York: Praeger. 111-136.

[16] Holmes, J (1995). Women, men and politeness. Longman, London.

[17] Wardhaugh, R. (1998). An introduction to sociolinguistics. Blackwell publishers. Third edition.

[18] Nunan, D. (1996). Hidden voices: Insidersí perspectives on classroom interaction. In K. Bailey and D. Nunan (Eds.), Voices From the Language Classroom (pp. 41-56). New York: Cambridge University Press.

[19] Rugg, G. \& Petre, M. (2007) A Gentle guide to research methods. Open University Press. England.

[20] Seliger, H. W. \& Shohamy, E. (2008) Second language research methods. Oxford University Press, New York.

[21] Paulston, C.B. (1976). Pronouns of address in Swedish: social class semantics and a changing system. Language in Society 5, 359386.

[22] Trudgill, P. (1983). Sociolinguistics: An Introduction to Language and Society. Harmondsworth: Penguin.

[23] Chaika, E. (1982). Language the Social Mirror. Rowley, MA: Newbury House. 
[24] Graesser, A., Long, D. \& J. Mio (1989) What are the cognitive and conceptual components of humorous text? Poetics 18: 143-163.

[25] Levine, Donald N. (1985) The Flight from Ambiguity. Essays in Social and Cultural Theory. Chicago: The University of Chicago Press.

[26] Quirk , R., Greenbaum, S., Leech, G., and Svartvik, J. (1985) A Comprehensive Grammar of the English Language. Longman, London.

[27] (n.d.) Cross-cultural communication strategies. Conflict research consortium, University of Colorado, USA. Retrieved April 10, 2011 from http://www.colorado.edu/conflict/peace/treatment/xcolcomm.htm

\section{Appendix 1}

Frequency of linguistic features used based on gender.

\begin{tabular}{llll}
\hline & & Frequency & \\
No. & Types & Men & Women \\
\hline 1 & Terms of address & 0 & 5 \\
1 & Questions & 5 & 13 \\
2 & Fillers & 2 & 1 \\
3 & Hedges & 3 & 2 \\
4 & Intensifiers & 0 & 0 \\
5 & Affirmative & 3 & 1 \\
6 & Adjective types & 1 & 5 \\
\hline
\end{tabular}

\section{Appendix 2}

Semi-structured interview questions

1. What form of address do you use to address your friends (other parents)?

2. Why do you use this form of address?

3. How do you address your spouse? Why?

4. What is your opinion about men's/women's speech in terms of politeness?

5. What is your opinion about men's/women's speech in terms of its directness?

6. Based on your experience in communicating with other people, is there anyone who has been hurt by your words? Why?

7. What are the common topics of conversation among men/women? 